\title{
Health-related quality of life and post- traumatic stress disorder in inpatients injured in the Ludian earthquake: a longitudinal study
}

Wanqiu Yang ${ }^{1 *}$ D, Ke Cui ${ }^{2}$, Timothy $\mathrm{Sim}^{3}$, Jun Zhang ${ }^{4}$, Yanchun Yang ${ }^{4}$ and Xiaohong Ma $a^{4,5,6 *}$

\begin{abstract}
Background: The aim of this longitudinal study was to identify risk factors for posttraumatic stress disorder (PTSD) in inpatients injured in the Ludian earthquake and examine the relationship between PTSD symptoms and healthrelated quality of life (HRQOL) following the earthquake.

Methods: Three assessments were performed during an 18-month follow-up period. In total, one-hundred forty-seven inpatients of one-hundred seventy-four inpatients (85\% of the initial sample) underwent all the assessments. Injured inpatients admitted to the No. 1 People's Hospital of Zhaotong City after a severe earthquake (6.5 on the Richter scale) were enrolled in the study and assessed using the Posttraumatic Stress Disorder Checklist-Civilian Version, Clinician-Administered Posttraumatic Stress Disorder Scale, and Medical Outcomes Study Short Form-36 Scale.

Results: At the first, third and eighteenth months after the earthquake, the prevalence rates for PTSD were 23,14 , and $7 \%$, respectively. In a regression model, bereavement, history of major diseases, and severe injury in the earthquake were associated with severe PTSD symptoms. HRQOL was negatively correlated with PTSD symptoms. Compared to that of Chinese norms, participants' HRQoL was significantly lower in all eight HRQoL domains of the Medical Outcomes Study Short Form-36 Scale.

Conclusions: The findings suggest that a substantial proportion of inpatients injured in the earthquake experienced severe PTSD symptoms and poor HRQoL. Therefore, early preventive programs and interventions should be implemented following disasters, to reduce PTSD and improve HRQOL in injured individuals.
\end{abstract}

Keywords: Injured inpatients, Posttraumatic stress disorder, Health-related quality of life, Disasters

\footnotetext{
* Correspondence: yangwanqiu@ynu.edu.cn; maxiaohong@scu.edu.cn

${ }^{1}$ The Mental Health Center, Yunnan University, Kunming 650091, People's Republic of China

${ }^{4}$ The Mental Health Center, West China Hospital of Sichuan University, Chengdu 610041, People's Republic of China

Full list of author information is available at the end of the article
}

(C) The Author(s). 2020 Open Access This article is licensed under a Creative Commons Attribution 4.0 International License, which permits use, sharing, adaptation, distribution and reproduction in any medium or format, as long as you give appropriate credit to the original author(s) and the source, provide a link to the Creative Commons licence, and indicate if changes were made. The images or other third party material in this article are included in the article's Creative Commons licence, unless indicated otherwise in a credit line to the material. If material is not included in the article's Creative Commons licence and your intended use is not permitted by statutory regulation or exceeds the permitted use, you will need to obtain permission directly from the copyright holder. To view a copy of this licence, visit http://creativecommons.org/licenses/by/4.0/. The Creative Commons Public Domain Dedication waiver (http://creativecommons.org/publicdomain/zero/1.0/) applies to the data made available in this article, unless otherwise stated in a credit line to the data. 


\section{Background}

Natural disasters, such as earthquakes, cyclones, floods, and tsunamis, lead to not only direct economic loss, death, and physical injury but also long-term adverse psychological outcomes [1]. A proportion of survivors experience long-term distress and psychopathology including posttraumatic stress disorder (PTSD), depressive disorder, and other disorders [2]. PTSD is the most prevalent of these adverse psychological outcomes [3, 4]. The consequences of disaster exposure, such as the presence of physical injury, fear of death, the loss of loved ones, and property loss, have been shown to be stronger predictors of PTSD relative to disaster type [4]. In addition, seriously injured trauma-exposed patients who require extended inpatient hospital admission could be at the greatest risk of PTSD development $[5,6]$.

The current literature suggests that approximately 10 to $40 \%$ of injured survivors will develop PTSD $[5,7,8]$. Some studies conducted after the Wenchuan earthquake in China reported that, 1 month after the disaster, the prevalence rates for PTSD in injured inpatients ranged from 17.1 to $45.9 \%$ [9-11]. Differences in PTSD prevalence rates between studies could result from differences in trauma types, degrees of trauma exposure, participant characteristics, the instruments used to measure PTSD, and the time from trauma to PTSD assessment $[12,13]$. In China, PTSD studies involving survivors of natural disasters have focused mainly on hospitalization, particularly those examining the 2008 Wenchuan earthquake. However, few studies have explored long-term outcomes, such as $1-2$ year or several years after disasters, for survivors who are at high risk of PTSD [14, 15]. Therefore, prospective follow-up of injured survivors is required to identify risk factors for PTSD.

PTSD is independently related to a broad profile of functional impairments and diminished quality of life (QoL) following injury [16, 17]. Reduced QoL has been observed after catastrophic events, such as natural disasters, and could be linked to material loss, somatic injury, and psychological distress $[18,19]$. Health-related quality of life (HRQoL) is a narrow concept of QoL and pertains to the physiological, psychological, and functional aspects of well-being from the individuals' own perspective [20]. Recent studies demonstrated that depression, anxiety disorders, and PTSD could exert a profound effect on HRQoL [21, 22]. Moreover, HRQoL is negatively correlated with PTSD in survivors of natural disasters [2, $22,23]$. The recognition of risk factors for PTSD is essential for the early identification of individuals at increased risk of experiencing these outcomes, to improve their HRQoL [24].

The present study aimed to provide insight into the prevalence, course, and predictors of PTSD and elucidate the relationship between PTSD and HRQoL in inpatients injured in the Ludian earthquake, via a longitudinal follow-up study, in contrast to most previous studies based on cross-sectional analysis.

\section{Methods \\ Study setting}

On August 3, 2014, an earthquake (6.5 on the Richter scale) occurred in Yunnan Province of China, with 617 deaths, 112 missing persons, 3143 injuries, and 1,088, 400 victims. The epicenter was located in Zhaotong City, a medium-sized city located southwest of China. The region has experienced serious natural disasters in recent years and was hit by the YiLang earthquake (5.7 on the Richter scale) in 2012, the Ludian earthquake (6.5 on the Richter scale) in 2014, and a flood in 2016.

\section{Participants and procedures}

This longitudinal study included injured inpatients in the Ludian earthquake and treated at the No. 1 People's Hospital of Zhaotong City. Of approximately 600 injured patients, approximately 200 were discharged from the No. 1 People's Hospital of Zhaotong City within a week, and 125 were transferred to other hospitals because of the severity of their injuries. In total, 174 patients aged between 10 and 75 years fulfilled the following inclusion criteria: (I) suffered physical injury caused by the Ludian earthquake, (II) treatmented in the hospital for longer than 1 month, (III) had no history of alcohol dependence or addictive drug use; and (IV) had no current pregnancy or breastfeeding; however, 101 injured patients did not meet the inclusion criteria for the study (shown in Fig. 1).

In total, 174 patients participated in the baseline assessment, and 163 and 147 participated in the first and second follow-up assessments, respectively. The initial assessment was conducted at the No. 1 People's Hospital of Zhaotong between September and October 2014, approximately 1 month after the earthquake. The first follow-up assessment was conducted 3 months after the earthquake, between November and December 2014, and involved patient interviews at the hospital or resettlement sites, because most of patients had been discharged. Of the original 174 participants, 11 did not participate in the second assessment. The second followup assessment was conducted 18 months after the earthquake, in February 2016, in patients' communities. Of the original 174 participants, 27 did not participate in the third assessment. A flowchart of the study is shown in Fig. 1.

The study was approved by the ethics committee at $\mathrm{Si}$ chuan University in Chengdou, China (2014) and was performed in accordance with the Declaration of Helsinki and its later amendments. All participants provided informed consent. Data were collected via face-to- 


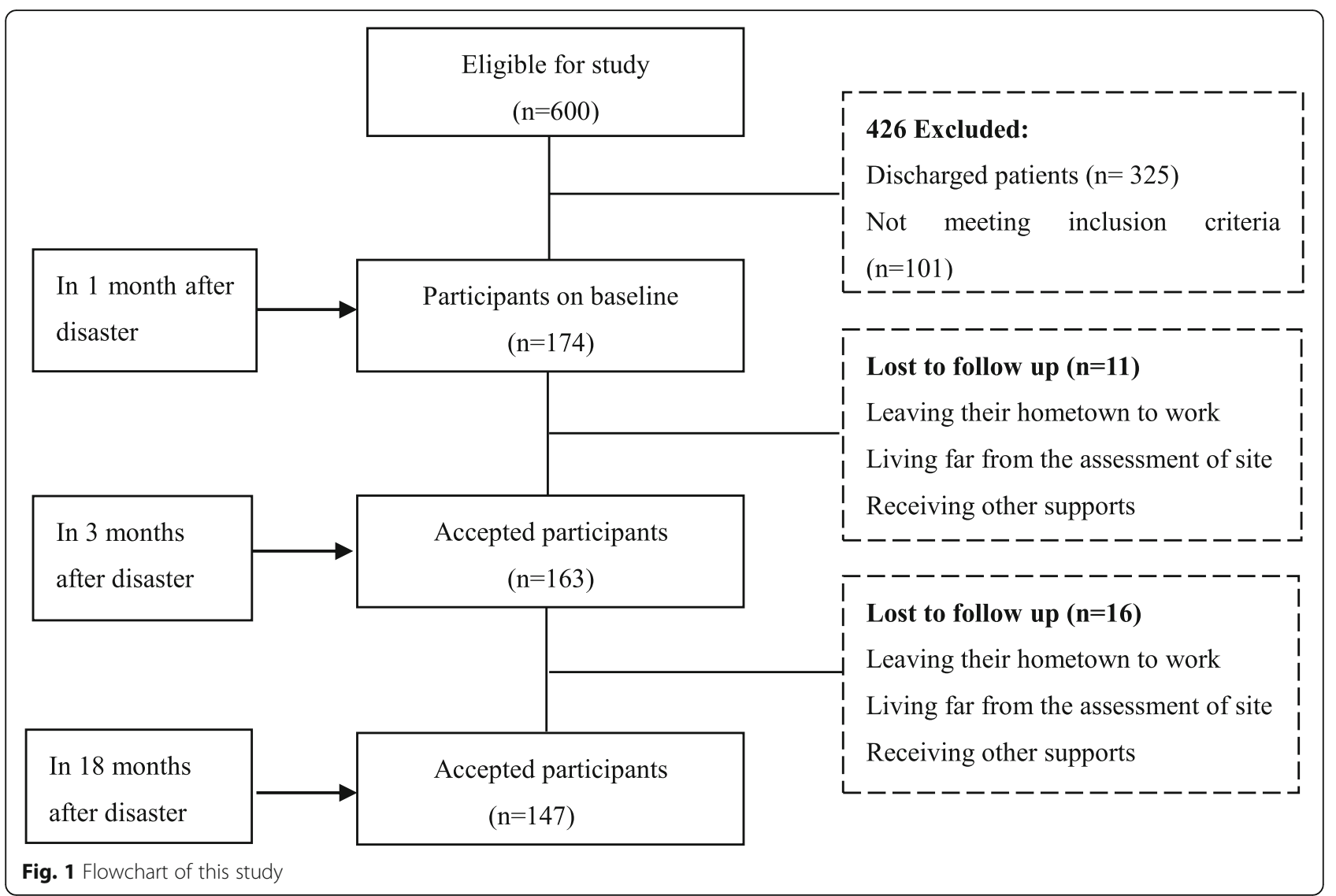

face interviews conducted by four local psychiatrists and individuals who held master's degrees in psychology from Sichuan university and were trained in group discussion and standardized data collection procedures. The four psychiatrists each held more than 5 years' work experience and reviewed the Diagnostic and Statistical Manual of Mental Disorders, Fourth Edition (DSM-IV) diagnostic criteria for PTSD and the Clinician -Administered Posttraumatic Stress Disorder Scale (CAPS) prior to the interviews.

\section{Measures}

Participants' demographic characteristics, including age, sex, ethnicity, educational level, marital status, occupation, earthquake-related disaster exposure, and experiences after the Ludian earthquake were measured via a self-report questionnaire, which included the following questions: (1) Was your house destroyed entirely in the earthquake? (2) Were you buried or did you witness the death of a family member in the earthquake? (3) Did a family member die in the earthquake? (4) Were you with your family members when the earthquake occurred? (5) Have you been diagnosed with any major disease such as hypertension, stroke, heart disease, diabetes, or tumor? (6) Did you experience any major life events, such as the death of a family member (child, spouse, or parent), serious injury, disability, or divorce, before the earthquake? All these questions were coded dichotomously as yes/no items (shown in Self-report Interview Questionnaire 1).

\section{Post-traumatic stress disorder checklist-civilian version}

The PTSD Checklist-Civilian Version (PCL-C) was used to measure self-reported trauma-related stress 1 and 3 months after the disaster. The PCL-C is a clinical selfassessment diagnostic scale consisting of 17 items that correspond to the fourth edition of criteria the Diagnostic and Statistical Manual of Mental Disorders (DSM-IV) [25]. Responses are provided using a five-point Likerttype scale ranging from 1 (not at all) to 5 (extremely), with higher scores indicating more severe posttraumatic stress. Total symptom severity scores range from 17 to 85 , and a cut-off point of 50 was recommended for the diagnosis of PTSD in Chinese sample [26, 27]. With a cut-off point of 50 , sensitivity was 0.78 , specificity was 0.86 , and diagnostic efficiency was 0.83 . The PCL-C scores were strongly correlated with the Clinician -Administered PTSD Scale (CAPS) scores. The correlation coefficient was 0.93 , and diagnostic efficiency was 0.90 $[28,29]$. The PCL-C has been used widely in various Chinese populations and has shown high internal consistency, with Cronbach's $\alpha$ of 0.96 [30, 31]. 


\section{Clinician -Administered Posttraumatic Stress disorder Scale (CAPS)}

Participants underwent a structured clinical interview via the CAPS, which was based on 1994 DSM-IV Diagnoses (American Psychiatric Association) [32], 18 months after the earthquake. The CAPS is recognized as one of the gold standards for the diagnosis of PTSD [33]. (The CAPS includes 30 items, with responses provided using a four-point Likert-type scale ranging from 1 (never) to 4 (routinely). The CAPS includes Criterion A (exposure to a traumatic event), Criteria B-D (core symptom clusters of re-experiencing, numbing, avoidance, and hyperarousal), Criterion E (chronology), Criterion $\mathrm{F}$ (functional impairment), and associated guilt and dissociation and assesses current and lifetime PTSD symptom status. The scale includes three subscales: reexperiencing, avoidance, and hyperarousal. Total scores range from 0 to 136, and patients with CAPS scores exceeding 65 are categorized as having PTSD, while those with CAPS scores exceeding 80 are categorized as having extreme PTSD [32]. The CAPS has shown good reliability and validity in Chinese samples [34, 35]. Moreover, Li et al. reported Cronbach's $\alpha$ s between 0.80 and 0.90 and convergent validity of 0.70 for the Chinese version of the CAPS [33, 35].

All assessments performed at 1 month $(N=174)$ and 3 months $(N=163)$ after the disaster involved the PCL-C, while those performed at 18 months $(N=147)$ after the disaster involved the CAPS, administered by four psychiatrists to confirm PTSD diagnosis. To evaluate investigator reliability, we selected 20 of the 147 cases at random for independent assessment by the four psychiatrists. Two of the 20 cases showed inconsistency in the diagnoses formed by the four psychiatrists. Therefore, we concluded that investigator reliability was $90 \%$, and the diagnoses formed by the four psychiatrists showed good inter-rater reliability $\left(W=.93, \chi^{2}=32.45, P<.001\right)$. It reasonable to speculate that the clinical diagnosis of patients at 18-month are more valuable. Thus, the results of 18-month were reported in detail.

\section{The medical outcomes study 36 -item short form health survey}

The Medical Outcomes Study 36-Item Short Form Health Survey (SF-36) is widely used in HRQoL research and has been validated and tested for reliability in some studies and used extensively to evaluate functional and QoL outcomes in injured individuals $[6,18]$. The scale consists of two dimensions: the physical component summary and the mental component summary. The physical component summary contains four subscales: physical functioning (PF); role physical (RP), which pertains to role limitations because of physical health problems; bodily pain (BP); and general health $(\mathrm{GH})$. The mental component summary contains four subscales: vitality (VT); social functioning (SF); role emotional (RE), which pertains to role limitations because of emotional problems; and mental health $(\mathrm{MH})$ [36]. Subscales are scored from 0 to 100, and higher scores indicate greater HRQoL. The Chinese version of the SF-36 is used widely in China, and Cronbach's $\alpha$ s for the scale have been reported between .70 and .80 , with convergent validity ranging from .66 to $.94[37,38]$.

\section{Statistical analysis}

All data were analyzed using SPSS for Windows (version 16.0). The results of the descriptive analyses are presented as central tendencies for continuous variables and frequencies for categorical variables. The data for scores of the PCL-C, the CAPS and the SF-36 all passed the normality test. We performed $t$ tests for continuous data and 2-sided Fisher exact test for categorical data, to compare differences between two groups (with PTSD and without PTSD at 18 months). Single sample t-test was used to compare the difference between patients and Chinese norms on the SF- 36 scale. The prevalence rates for PTSD were described as a percentage and the 95\% confidence intervals for PTSD prevalence rates were calculated using binomial the distribution of these rate. The multivariate logistic regression analysis was performed to identify the independent effects of the predictors of PTSD (dependent variables). In all tests, coefficient values, odds ratios (ORs), and 95\% confidence intervals (CIs) were used to quantify correlation strength. All tests were 2-tailed, and statistical significance was set at $P \leq .05$.

\section{Results}

\section{Demographic data and disaster exposure characteristics}

Table 1 shows the participant data collected at 1 month, 3 months, and 18 months. Of the 174 patients assessed 1 month after the earthquake, 74 were men, 100 were women, 103 were married, 55 were unmarried, 16 were divorced, and 140 were Han, who is main ethnic group of the local area. The patients' mean age ( \pm sd) was $46 \pm$ 18.4 years old, and their ages ranged from 10 to 88 years. The numbers of patients who had completed primary school, middle school, and high school and above were 56, 39, and 19, respectively, and 60 patients were illiterate. Most of the participants were peasants $(n=$ 154). With respect to disaster exposure, 49 of 174 patients had experienced burial and bereavement, 24 patients were separated from their families, and 23 patients were affected by severe injury. The numbers of patients who reported a history of major diseases and life events were 27 and 52 , respectively. 
Table 1 Demographic data and disaster exposure characteristics of the injured in 3, 6 and 18 months

\begin{tabular}{|c|c|c|c|c|}
\hline & Variable & $\begin{array}{l}1 \text { month } \mathrm{n}(\%) \\
(\boldsymbol{N}=174)\end{array}$ & $\begin{array}{l}3 \text { months n(\%) } \\
(\boldsymbol{N}=163)\end{array}$ & $\begin{array}{l}18 \text { months } \mathrm{n}(\%) \\
(\boldsymbol{N}=147)\end{array}$ \\
\hline Age & & $46 \pm 18.4$ & $45 \pm 18.3$ & $46 \pm 17.6$ \\
\hline \multirow[t]{2}{*}{ Gender } & Male & $74(43)$ & $74(45)$ & $67(46)$ \\
\hline & Female & $100(57)$ & $89(55)$ & $80(54)$ \\
\hline \multirow[t]{2}{*}{ Ethnic group } & Han & $165(95)$ & $156(96)$ & $140(95)$ \\
\hline & Non-Han & $9(5)$ & $7(4)$ & $7(5)$ \\
\hline \multirow[t]{4}{*}{ Education } & Illiteracy & $60(35)$ & $55(34)$ & $46(33)$ \\
\hline & Primary school & $56(32)$ & $54(33)$ & $54(37)$ \\
\hline & Middle school & $39(22)$ & $37(23)$ & $37(25)$ \\
\hline & High school and above & $19(11)$ & $17(10)$ & $10(5)$ \\
\hline \multirow[t]{2}{*}{ occupation } & Peasant & $154(89)$ & $143(88)$ & $132(90)$ \\
\hline & Others & $20(11)$ & $20(12)$ & $15(10)$ \\
\hline \multirow[t]{3}{*}{ Marital status } & Single & $55(32)$ & $55(34)$ & $47(32)$ \\
\hline & Married & $103(59)$ & $93(57)$ & $86(59)$ \\
\hline & Divorced & $16(9)$ & $15(9)$ & $14(9)$ \\
\hline \multirow[t]{2}{*}{ House collapsed completely } & NO & $58(33)$ & $47(29)$ & $39(27)$ \\
\hline & YES & $116(67)$ & $116(71)$ & $108(73)$ \\
\hline \multirow[t]{2}{*}{ Buried experience } & NO & $125(72)$ & $119(73)$ & $110(75)$ \\
\hline & YES & $49(28)$ & $44(27)$ & $37(25)$ \\
\hline \multirow[t]{2}{*}{ Bereavement } & NO & $125(72)$ & $119(73)$ & $110(75)$ \\
\hline & YES & $49(28)$ & $44(27)$ & $37(25)$ \\
\hline \multirow[t]{2}{*}{ History of major diseases } & NO & $147(85)$ & $140(86)$ & $124(84)$ \\
\hline & YES & $27(15)$ & $23(14)$ & $23(16)$ \\
\hline \multirow[t]{2}{*}{ Separation from family } & NO & $150(86)$ & $144(88)$ & $134(91)$ \\
\hline & YES & $24(14)$ & $19(12)$ & $13(9)$ \\
\hline \multirow[t]{2}{*}{ Major life events before the disaster } & NO & $122(70)$ & $116(71)$ & $104(71)$ \\
\hline & YES & $52(30)$ & $47(29)$ & $43(29)$ \\
\hline \multirow[t]{2}{*}{ Severe injury } & NO & $23(13)$ & $22(14)$ & $18(12)$ \\
\hline & YES & $152(87)$ & $141(86)$ & $129(88)$ \\
\hline
\end{tabular}

\section{Analysis of dropout}

As shown in Table 1 and Fig. 1, during follow-up, 11 (6\%) and 27 (16\%) of participants did not attend the 3month and 18-month evaluations, respectively. We analyzed the participants' circumstances before dropout, to clarify the effect of missing data and explore the causes of dropout. Specifically, we used t tests to compare PCL$\mathrm{C}$ scores between the dropout and follow-up groups. Baseline PCL-C scores for participants who did not attend follow up at 3 months $(n=11)$ did not differ significantly from that of participants who attended follow-up assessment ( $n=163 ; 41 \pm 11.5$ versus $40 \pm 13.7, P>.05$ ). In addition, of the participants who attended follow up at 3 months, PCL-C scores for those who did not attend follow up $(n=16)$ at 18 months did not differ significantly from that of participants who attended follow-up assessment ( $n=147 ; 31 \pm 14.9$ versus $38 \pm 13.7, P>.05$ ).
Of the participants who dropped out, 74\% (20/27) were men and $26 \%(7 / 27)$ were women. Of the participants who dropped out, 7\% (2/27) were seriously injured and 93\% (25/27) were not seriously injured.

Moreover, to understand the reasons for dropout, we randomly selected eight of the 27 participants who had dropped out and interviewed them by telephone to ask about their recovery status and the reasons why they did not wish to participate in the assessments. Three main reasons were reported: some participants had left their settlements or homes to work in other cities; some participants lived far from the assessment of site, which was approximately $4 \mathrm{~h}$ ' walk away; and two participants had begun to receive financial and health support from other social organizations. Therefore, it is reasonable to speculate that there were valid reasons for attrition. Most men who dropped out had left to work in larger cities. 
Further, some participants lived in scattered areas and most lived high in the mountains, and it was difficult for them to attend assessments at community health centers. In addition, both follow-up interviews were conducted in autumn and winter; therefore, it was difficult for participants to attend. Moreover, the rehabilitation assessments might not have provided sufficient support to patients, and participants received more support from the government or other social organizations.

\section{The prevalence of PTSD at 1 month, 3 months, and 18 months after the earthquake}

The prevalence rates for PTSD assessed by PCL-C at 1 month and 3 months after the earthquake were (40/174) 23\%(95\% CI: 17\%, 29\%)and (22/163)14\%(95\% CI: 7\%, $16 \%)$ respectively. Further, the prevalence of PTSD was (10/147) 7\%(95\% CI: 3\%, 10\%)at 18 months, according the criteria of PTSD (CAPS Scale). Therefore, the overall prevalence of PTSD decreased gradually following the earthquake. In addition, we checked the individuals with PTSD at 3-month and 18-month. Seventeen of twentytwo individuals who had PTSD at the 3-month assessment were screened positive-PTSD at the 1-month and eight of twenty-two individuals were still diagnosed with PTSD at the 18-month. Meanwhile, seven and eight of ten individuals who had PTSD at the18-month assessment were screened positive-PTSD at the 1-month and 3-month, respectively.

\section{Comparison of demographic characteristics and disaster exposure between the PTSD and non-PTSD groups at 18 months}

The differences in demographic characteristics between the PTSD $(n=10)$ and non-PTSD $(n=137)$ groups 18 months after the disaster are summarized in Table 2. There were no significant differences between the two groups, according to age, gender, educational level, ethnicity, occupation, or marital status. In addition, the two groups did not differ significantly according to the consequences of disaster exposure, such as houses collapsing completely and separation from family, or the experience of major life events before the disaster. However, the proportions of participants who had experienced being buried 7/10 (70\%) versus 30/137 (22\%) $(P=$ $0.003)$, being bereaved $7 / 10(70 \%)$ versus $39 / 137$ (29\%) $(P=0.011)$, a history of major diseases $7 / 10(70 \%)$ versus $16 / 137(12 \%)(P<0.001)$, and sustained severe injuries $7 /$ $10(70 \%)$ versus32/137 $(23 \%)(P=0.004)$ in the PTSD group were significantly higher than those observed in the non-PTSD group. Moreover, the proportion of participants in the PTSD group who had undergone physical rehabilitation at 18 months was significantly lower than that observed in the non-PTSD group 6/10 (60\%) versus $122 / 137$ (89\%) $(P=0.048)$.

\section{Risk factors for 18-month PTSD after earthquake}

The results of the logistic regression to identify factors that predicted PTSD were as follows (Table 3). All significant variables $(P<.05)$ in the univariate analyses were included in the logistic regression model to identify the independent role of each predictor variable after adjustment, including bereavement, a history of major diseases, severe injury, experience of being buried and rehabilitation at 18 months. The results of the logistic regression analysis indicated that risk factors for PTSD included bereavement $(\mathrm{OR}=29.26, \mathrm{CI}: 3.125-274.046)$, a history of major diseases $(\mathrm{OR}=15.92, \mathrm{CI}$ : 1.850 136.934), and severe injury (OR $=0.039$, CI: $0.005-$ 0.309 ). The experience of being buried $(\mathrm{OR}=1.323, \mathrm{CI}$ : $0.123-14.20)$ and rehabilitation at 18 months $(\mathrm{OR}=$ 0.144, CI: $0.019,1.115)$ were not risk factors for PTSD.

\section{Assessment of HRQoL 18 months after the earthquake}

There were differences in health status between the participants $(N=147)$ and the general Chinese population $(N=4251)$. In our study, 46 and $54 \%$ of patients was for male and female and the average age $( \pm \mathrm{sd})$ was $46 \pm$ 17.6 years, old, while among the 4251 respondents of the general Chinese population, male and female respondents accounted for 51\% (2154) and 49\% (2097) and the average age ( \pm sd) was $41 \pm 17.3$ years old, ranging from $14 \sim 99$ years old $[36,39]$. The two groups differed significantly in all eight subscales of the SF-36 are summarized in Table 4. The participants' mean subscale scores were significantly lower relative to those observed in the general Chinese population (BP: $72.10 \pm 17.38$ versus $83.3 \pm 19.7, P<.001$; PF: $63.80 \pm 31.75$ versus $87.6 \pm 16.8$, $P<.001 ; \mathrm{RP}: 11.14 \pm 30.19$ versus $83.0 \pm 20.7, P<.001$; $\mathrm{GH}: \quad 47.5 \pm 15.23$ versus $68.2 \pm 19.4, \quad P<.001$; VT: $48.26 \pm 11.49$ versus $70.1 \pm 16.8, P<.001 ;$ SF: $78.26 \pm$ 19.42 versus $84.8 \pm 16.6, P=.001$; RE: $23.19 \pm 42.15$ versus $85.3 \pm 17.7, P<.001$; $\mathrm{MH}: 57.00 \pm 8.93$ versus $78.8 \pm$ $15.4, P<.001)$. These data indicated that the health status of inpatients injured in the earthquake was poorer relative to that of the general Chinese population.

\section{Relationship between PTSD and QoL domains 18 months after the earthquake}

The results of the analysis of correlations between PTSD and the domains of HRQoL showed that CAPS scores were negatively correlated with scores for all eight SF-36 subscales including $\mathrm{BP}, \mathrm{PF}, \mathrm{RP}, \mathrm{GH}, \mathrm{VT}, \mathrm{SF}, \mathrm{RE}$, and $\mathrm{MH}$. The correlation coefficients ranged from -.26 to -.53 , as shown in Table 5 .

\section{Discussion}

In this longitudinal study, we examined PTSD in inpatients injured in the Ludian earthquake. The prevalence rates for PTSD 1, 3, and 18 months after the earthquake 
Table 2 Demographics and disaster exposure of the injured with and without PTSD at 18 months post-disaster by univariate analyses

\begin{tabular}{|c|c|c|c|c|}
\hline Demographic & Characteristics & Non-PTSD group n(\%) $(\boldsymbol{N}=137)$ & PTSD group n(\%) $(\boldsymbol{N}=10)$ & $P$-value \\
\hline$\overline{\text { Age }}$ & & $46 \pm 17.9$ & $44 \pm 14.8$ & 0.094 \\
\hline \multirow[t]{2}{*}{ Gender } & male & $63(46)$ & $4(40)$ & 0.755 \\
\hline & female & $74(54)$ & $6(60)$ & \\
\hline \multirow[t]{2}{*}{ Ethnic group } & Han & $130(95)$ & $10(100)$ & $>0.999$ \\
\hline & Non-Han & $7(5)$ & 0 & \\
\hline \multirow[t]{4}{*}{ Education level } & Illiteracy & $44(32)$ & $2(20)$ & 0.661 \\
\hline & Primary school & $49(36)$ & $5(50)$ & \\
\hline & Middle school & $35(26)$ & $2(20)$ & \\
\hline & High school and above & $9(6)$ & $1(10)$ & \\
\hline \multirow[t]{2}{*}{ occupation } & Peasant & $122(89)$ & $10(100)$ & 0.599 \\
\hline & others & $15(11)$ & 0 & \\
\hline \multirow[t]{3}{*}{ Marital status } & Single & $45(33)$ & $2(20)$ & 0.493 \\
\hline & Married & $78(57)$ & $8(80)$ & \\
\hline & Divorced & $14(10)$ & 0 & \\
\hline \multirow[t]{2}{*}{ Houses collapsed completely } & No & $37(27)$ & $2(20)$ & $>0.999$ \\
\hline & Yes & $100(73)$ & $8(80)$ & \\
\hline \multirow[t]{2}{*}{ Buried experience } & No & $107(78)$ & $3(30)$ & 0.003 \\
\hline & Yes & $30(22)$ & $7(70)$ & \\
\hline \multirow[t]{2}{*}{ Bereavement } & No & $98(72)$ & $3(30)$ & 0.011 \\
\hline & Yes & $39(28)$ & $7(70)$ & \\
\hline \multirow[t]{2}{*}{ History of major diseases } & No & $121(88)$ & $3(30)$ & 0.000 \\
\hline & Yes & $16(12)$ & $7(70)$ & \\
\hline \multirow[t]{2}{*}{ Separation from family } & No & $126(92)$ & $8(80)$ & 0.217 \\
\hline & Yes & $11(8)$ & $2(20)$ & \\
\hline \multirow[t]{2}{*}{ Major life events before the disaster } & No & $97(71)$ & $7(70)$ & $>0.999$ \\
\hline & Yes & $40(29)$ & $3(30)$ & \\
\hline \multirow[t]{2}{*}{ Severe injury } & No & $105(77)$ & $3(30)$ & 0.004 \\
\hline & Yes & $32(23)$ & $7(70)$ & \\
\hline \multirow[t]{2}{*}{ Rehabilitation at 18 months } & No & $15(11)$ & $4(40)$ & 0.026 \\
\hline & Yes & $122(89)$ & $6(60)$ & \\
\hline
\end{tabular}

Table 3 Relationship between main variables and PTSD analyzed by logistic regression

\begin{tabular}{|c|c|c|c|}
\hline Variables & & OR $(95 \% \mathrm{Cl})$ & $\boldsymbol{P}$-value \\
\hline \multirow[t]{2}{*}{ Buried experience } & $\mathrm{NO}$ & 1 & \\
\hline & YES & $1.323(0.123 \sim 14.200)$ & 0.817 \\
\hline \multirow[t]{2}{*}{ Bereavement } & NO & 1 & \\
\hline & YES & 29.263(3.125 274.046) & 0.003 \\
\hline \multirow[t]{2}{*}{ History of major diseases } & NO & 1 & \\
\hline & YES & $15.916(1.850 \sim 136.934)$ & 0.012 \\
\hline \multirow[t]{2}{*}{ Severe injury } & YES & 1 & 0.002 \\
\hline & NO & $0.039(0.005 \sim 0.309)$ & \\
\hline \multirow[t]{2}{*}{ Rehabilitation at 18 months } & YES & 1 & 0.063 \\
\hline & NO & $0.144(0.019 \sim 1.115)$ & \\
\hline
\end{tabular}

Abbreviations: $\mathrm{Cl}$ confidence interval, PTSD posttraumatic stress disorder were 23,14 , and $7 \%$, respectively. Gao et al. reported that the prevalence rates for PTSD in survivors of bodily injury 1 month after the Wenchuan earthquake ranged from 35.56 to $45.90 \%$ [9, 10]. Moreover, Wang et al. found that, 3 months after the disaster, the prevalence rate for PTSD was $18.8 \%$ and the PTSD prevalence rate was $7.2 \%$ [40]. In addition, Zatizck et al. reported that more than $20 \%$ of injured trauma survivors displayed PTSD symptoms 12 months after acute care inpatient hospitalization in the USA [6], and Shalev et al. showed that the incidence rate for PTSD in inpatients 6 months after the disaster was $25.5 \%$ [5]. Several factors could have contributed to relatively low PTSD prevalence rate observed in the current study. For example, the development of PTSD is related to the characteristics of the trauma and the extent of physical injury [41], and more 
Table 4 Comparison of HRQOL mean scores among the injured and general Chinese at 18 months post-disaster

\begin{tabular}{|c|c|c|c|c|}
\hline & $\begin{array}{l}\text { The injured } \\
(M e a n \pm \text { SD) } \\
(\boldsymbol{N}=147)\end{array}$ & $\begin{array}{l}\text { The Chinese norm } \\
\text { (Mean } \pm \text { SD) } \\
(\boldsymbol{N}=4251)\end{array}$ & $t$ & $\boldsymbol{P}$-value \\
\hline \multicolumn{5}{|l|}{ Physical health domains } \\
\hline Bodily Pain (BP) & $72.10 \pm 17.38$ & $83.3 \pm 19.7$ & -6.245 & 0.000 \\
\hline Physical Functioning (PF) & $63.80 \pm 31.75$ & $87.6 \pm 16.8$ & -6.917 & 0.000 \\
\hline Role-Physical (RP) & $11.14 \pm 30.19$ & $83.0 \pm 20.7$ & -22.822 & 0.000 \\
\hline General Health (GH) & $47.5 \pm 15.23$ & $68.2 \pm 19.4$ & -9.635 & 0.000 \\
\hline \multicolumn{5}{|l|}{ Mental health domains } \\
\hline Vitality (VT) & $48.26 \pm 11.49$ & $70.1 \pm 16.8$ & -18.225 & 0.000 \\
\hline Social Functioning (SF) & $78.26 \pm 19.42$ & $84.8 \pm 16.6$ & -3.411 & 0.001 \\
\hline Role-Emotional (RE) & $23.19 \pm 42.15$ & $85.3 \pm 17.7$ & -14.135 & 0.000 \\
\hline Mental Health (MH) & $57.00 \pm 8.93$ & $78.8 \pm 15.4$ & -23.423 & 0.000 \\
\hline
\end{tabular}

severe trauma generally exerts a greater impact on survivors relative to less severe trauma [5]. In addition, differences between PTSD screening instruments and their associated cut-off values increase the risk of assessment bias and reduce the reliability of prevalence estimates. Most studies have used a cut-off score of 41 for the PCL-C, while we used the recommended cut off score of $50[24,25]$. Moreover, the current study used the CAPS to assess PTSD 18 months after the disaster, unlike previous studies.

Longitudinal studies are essential in understanding psychopathology following disasters. The reduction in the prevalence rate for PTSD from 23 to $7 \%$ in the current study was greater relative to that of the natural progression of untreated PTSD. One factor that could have contributed to the recovery observed in the current study was the provision of efficient medical and emergency assistance in response to the Ludian earthquake, based on lessons learned from the 2008 Wenchuan earthquake [42]. Another reason for this finding could

Table 5 Relationship between PTSD and domains of RHQoL at 18 months post-disaster by correlation analysis

\begin{tabular}{lll}
\hline & $\boldsymbol{r}$ & $\boldsymbol{P}$-value \\
\hline Physical health domains & & \\
Bodily Pain (BP) & -0.372 & $<0.0001$ \\
Physical Functioning (PF) & -0.529 & $<0.0001$ \\
Role-Physical (RP) & -0.320 & $<0.0002$ \\
General Health (GH) & -0.448 & $<0.0001$ \\
Mental health domains & & \\
Vitality (VT) & -0.422 & $<0.0001$ \\
Social Functioning (SF) & -0.482 & $<0.0001$ \\
Role-Emotional (RE) & -0.255 & 0.014 \\
Mental Health (MH) & -0.325 & 0.002 \\
\hline
\end{tabular}

be that, after the earthquake, psychological rescue teams were dispatched to the disaster area immediately to provide psychological services for injured hospital patients for approximately 3 months [43]. However, we cannot rule out the possibility that some participants recover from PTSD naturally without treatment, and it is important to determine whether early treatment leads to better outcomes relative to those observed with delayed or no treatment.

Multiple risk factors for PTSD in injured adults have been investigated $[5,6,41,44]$. In the current study, we identified three risk factors for PTSD, including bereavement, history of major diseases and severe injury, but we did not find significant relationships between PTSD and demographic characteristics, such as previous life events, or property damage. An overwhelming majority of studies examining post-disaster PTSD have used crosssectional study designs and reported substantially heterogeneous results [45]. However, the current study was longitudinal and included assessments at 1, 3, and 18 months after the disaster. The severity of injury was an important factor influencing PTSD symptoms [5, 7], and survivors who reported both injury and bereavement showed a significantly higher risk of PTSD relative to those who had not experienced injury or bereavement [7, 46]. Injury severity, bereavement, and history of major diseases could exert stronger effects on PTSD development relative to those exerted by demographic characteristics; however, future in-depth studies with larger samples are required to confirm these relationships.

To our knowledge, this was the first study to examine the relationship between PTSD and HRQoL in injured inpatients after a natural disaster in China. Many studies have shown that greater PTSD severity was associated with poorer psychosocial and physical HRQoL [2, 3, 39]. In the current study, HRQoL in injured survivors across both mental and physical dimensions was negatively 
correlated with PTSD. It is understandable that PTSD symptoms, such as intrusive thoughts, hypervigilance and nightmares, could affect social function and satisfaction with life. However, physical problems, such as pain and disability result in role limitations, and this could lead to emotional problems, which constitute known psychiatric impairment [40,47]. Therefore, the physical dimensions of HRQoL could affect PTSD symptoms. Moreover, PTSD symptoms and HRQoL interact mutually, as other life events, such as divorce and job loss, worsen PTSD symptoms [47]. Therefore, future studies should focus on the long-term mutual interaction between PTSD and HRQoL following disasters.

In the current study, participants' SF-36 scores in all eight QoL domains 18 months after the disaster were significantly lower relative to the Chinese norm-based score. Norm-based scoring of SF-36 scales is recommended to facilitate the interpretation of results across measures [48]. The greatest differences between the participants' scores and the Chinese norm-based score were found in RP, GH, VT, RE, and $\mathrm{MH}$, with the means of these subscales all below 50 in the current study. Low SF-36 scores indicate that people find it difficult to make use of social support [49]. However, social support is vital for mental health, and negative social support could increase the risk of PTSD development [50]. Therefore, the current findings suggest a need for psychological intervention and the provision of social support for inpatients after disasters.

\section{Conclusion}

Exposure to trauma, such as bereavement, a history of major diseases, and severe injury could exert negative effects on patients injured in earthquakes and increase the long-term risk of PTSD. Moreover, HRQoL was negatively correlated with PTSD symptoms in inpatients injured in the earthquake in the current study. In addition, the participants' levels of HRQoL were significantly lower relative to those of the general Chinese population. In future research, it would be appropriate to design and evaluate early interventions for implementation following disasters, to reduce PTSD symptoms and improve QoL for injured inpatients.

\section{Study limitations and strengths}

The study was subject to some limitations. First, although PCL-C scores are very strongly correlated with CAPS scores, differences between the results obtained via these diagnostic tools for PTSD remain. In the comprehensive assessment of PTSD, the CAPS is one of the gold standards for use in PTSD diagnosis. In the current study, we used the PCL-C 1 and 3 months after the earthquake and the CAPS 18 months after the earthquake, because the PCL-C involves self-assessment and saves time, while the CAPS is used by psychiatrists and takes approximately $33 \pm 16 \mathrm{~min}$ to complete [33]. In the early post-disaster period, when responders are faced with heavy rescue tasks and a shortage of psychiatrists, the PCL-C is used as an evaluation tool to screen inpatients quickly. In addition, among the ten patients with PTSD at 18 months in our current study, seven and eight patients were positive PTSD at 1 month and 3 months, respectively, and only one patient was not screened for PTSD at 1 month and 3 months, respectively. This may indicate a relatively high degree of consistency between the PCL-C and the CAPS for assessment PTSD. Therefore, the above-mentioned limitation should be noted in future research and confirmed in future investigations. Second, self-report measures, such as the PCL and SF-36 used in the study, could involve potential information bias. In fact, response bias occurs in many areas of behavioral and medical research in which self-reported data are used [51]. Actually, the "response shift bias" phenomenon is a source of contamination in self-report measures, which can lead to inaccurate test ratings [52]. Moreover, our study sample size is relatively small. Therefore, the current findings should be confirmed in large samples in future studies. Third, another limitation was the high attrition rate in the follow-up research. One of the reasons for this was that some participants had moved to larger cities to work. Another reason was that it was difficult for participants to attend the assessment site in the community health center. Further, caution should be exercised when generalizing the results to other countries, different cultures, and different disaster scenarios. Finally, comparisons with Chinese general population data were limited to global mean testing since detailed data by gender and age categories or other confounders were not available. Therefore, although crude absolute SF-36 scale differences varied from 6 (social functioning) to 72 (role physical) and were all statistically significant $(p \leq 0.001)$ the present results should be considered with caution. Despite these limitations, this was the first study conducted in China to examine QoL and explore PTSD via followup research involving inpatients following a disaster. In addition, the findings could contribute to the design of evidence-based interventions to promote QoL and reduce the prevalence of PTSD in injured inpatients.

\section{Supplementary information}

Supplementary information accompanies this paper at https://doi.org/10. 1186/s12955-020-01470-5.

Additional file 1. Investigation of Earthquake Impact.

\section{Abbreviations}

QoL: Quality of life; HRQoL: Health-related quality of life; PTSD: Posttraumatic stress disorder; PCL-C: Post-Traumatic Stress Disorder Checklist-Civilian 
Version; CAPS: Clinician-Administered Posttraumatic Stress Disorder Scale; SF36: Medical Outcomes Study 36-Item Short Form Health Survey; DSMIV: Diagnostic and Statistical Manual of Mental Disorders, Fourth Edition

\section{Acknowledgements}

We wish to thank the staff at the No. 1 People's Hospital of Zhaotong City and Zhaotong Mental Health Center. This study was supported by the Civil Affairs Department of Yunnan Province. We thank all the participants and administrators of the selected units for their help with data collection.

\section{Authors' contributions}

Wanqiu Yang was a main investigator, designed the study, collected the data, wrote the paper, and analyzed the data. Xiaohong Ma was a main investigator, designed the study and analyzed and interpreted the data. Ke Cui, Timothy Sim, Jun Zhang and Yanchun Yang participated in writing the paper and revising the final draft. Other authors read and approved the final manuscript.

\section{Funding}

This work was supported by the grants from "Double TOP" of Yunnan University, the Hong Kong Polytechnic University, Department of Applied Social Sciences, under Grant 1-ZVE2 /2014.

\section{Availability of data and materials}

The datasets used and analyzed in the current study are available from the corresponding author on reasonable request.

\section{Ethics approval and consent to participate}

All procedures in the study were performed in accordance with the ethical standards of the institutional research committee. The study was approved by the Clinical Trails and Biomedical Ethics Committee of West China Hospital of Sichuan University in Chengdou, China (2014) and was conducted in accordance with the Declaration of Helsinki (1964) and its later amendments. All participants provided informed consent, and data were collected from September 2014 to February 2016.

\section{Consent for publication}

All participants signed informed consent forms and consented to publication of their individual data. In the case of children, a parent or legal guardian also provided consent for publication.

\section{Competing interests}

The authors declare that they have no competing interests.

\section{Author details}

${ }^{1}$ The Mental Health Center, Yunnan University, Kunming 650091, People's Republic of China. 'School of Public Administration, Sichuan University, Chengdu 610065, People's Republic of China. ${ }^{3}$ Department of Applied Social Sciences, The Hong Kong Polytechnic University, Hung Hom, Hong Kong. ${ }^{4}$ The Mental Health Center, West China Hospital of Sichuan University, Chengdu 610041, People's Republic of China. ${ }^{5}$ Psychiatric Laboratory and Mental Health Center, West China Hospital of Sichuan University, Chengdu 610041, People's Republic of China. ${ }^{6}$ West China Brain Research Center, West China Hospital of Sichuan University, Chengdu 610041, People's Republic of China.

Received: 25 June 2018 Accepted: 30 June 2020

Published online: 14 July 2020

\section{References}

1. $\mathrm{Xu} \mathrm{J,} \mathrm{Liao} \mathrm{Q.} \mathrm{Prevalence} \mathrm{and} \mathrm{predictors} \mathrm{of} \mathrm{posttraumatic} \mathrm{growth} \mathrm{among}$ adult survivors one year following 2008 Sichuan earthquake. J Affect Disord. 2011;133(1-2):274-80.

2. Nygaard E, Heir T. World assumptions, posttraumatic stress and quality of life after a natural disaster: a longitudinal study. Health Qual Life Outcomes. 2012;10(1):76-84.

3. Tsai KY, Chou P, Chou HC, Su TP, Lin SC, Lu MK, et al. Three-year follow-up study of the relationship between posttraumatic stress symptoms and quality of life among earthquake survivors in Yu-chi, Taiwan. J Psychiatr Res. 2007:41(1-2):90-6.
4. Norris FH, Friedman MJ, Watson PJ, Christopher MB, Eolia D, Krzysztof K, et al. 60,000 Disaster Victims Speak: Part I. An Empirical Review of the Empirical Literature, 1981-2001. Psychiatry. 2002;65(3):207-39.

5. Shalev AY, Peri T, Canetti L, Schreiber S. Predictors of PTSD in injured trauma survivors: a prospective study. Am J Psychiatry. 1996;153(2):219-25.

6. Zatzick DF, Rivara FP, Nathens $A B$, Jurkovich GJ, Wang J, Fan MY, et al. A nationwide US study of post-traumatic stress after hospitalization for physical injury. Psychol Med. 2007;37(10):1469-80.

7. Li YD, Assen J, Wang XY. The psychological effect of loss on the survivals of earthquake in Sichuan of China. Chin J Hebei Medical. 2011;33(9):2899-910.

8. Bryant RA, Harvey AG, Guthrie RM, Moulds ML. Acute psychophysiological arousal and posttraumatic stress disorder: a two-year prospective study. J Trauma Stress. 2003;16(5):439-43.

9. Ruggiero KJ, Ben KD, Scotti JR, Rabalais AE. Psychometric properties of the PTSD checklist—civilian version. J Trauma Stress. 2003;16(5):495-502.

10. Blanchard EB, Jonesalexander J, Buckley TC, Forneries CA. Psychometric properties of the PTSD checklist (PCL). J Behav Res Ther. 1996;34(8):669-3.

11. Kenardy J, Heron-Delaney M, Warren J, Brown E. The effect of mental health on long-term health-related quality of life following a road traffic crash: results from the UQ SUPPORT study. J Injury. 2015;46(5):883-90.

12. Chen L, Liu A. The incidence of posttraumatic stress disorder after floods: a meta-analysis. Disaster Med Public. 2015;9(3):329-33.

13. Dai WJ, Chen L, Lai ZW, Li Y, Wang JR, Liu AZ. The incidence of posttraumatic stress disorder among survivors after earthquakes: a systematic review and meta-analysis. BMC Psychiatry. 2016;16(1):188.

14. Chan CLW, Wang CW, Ho AHY, Qu ZY, Wang XY, Ran MS. Symptoms of posttraumatic stress disorder and depression among bereaved and nonbereaved survivors following the 2008 Sichuan earthquake. J Anxiety Disorder. 2012;26(6):673-9.

15. Hsiao YY, Chang WH, Ma IC, Wu CL, Chen PS, Yang YK, et al. Long-term PTSD risks in emergency medical technicians who responded to the 2016 Taiwan earthquake: a six-month observational follow-up study. Int J Environ Res Public Health. 2019;16(24):4983.

16. Holbrook TL, Anderson JP, Sieber WJ, Hoyt DB. Outcome after major trauma: 12-month and 18-month follow-up results from the trauma recovery project. J Trauma. 1999:46(5):771-3.

17. O'Donnell ML, Creamer M, Elliott P, Atkin C, Kossman T. Determinants of quality of life and role-related disability after injury: impact of acute psychological responses. J Trauma Acute Care Surg. 2005;59(6):1328-34.

18. Chou FHC, Chou P, Lin C, Su TT, Yang WCQ, Chien LC, et al. The relationship between quality of life and psychiatric impairment for a Taiwanese community post-earthquake. Qual Life Res. 2004;13(6):1089-97.

19. Kraemer B, Wittmann L, Jenewein J, Schnyder U. 2004 tsunami: long-term psychological consequences for Swiss tourists in the area at the time of the disaster. Aust N Z J Psychiatry. 2009:43(5):420-5.

20. Wyrwich KW, Bullinger M, Aaronson N, Hays RD, Patrik DL, Symonds T, et al. Estimating clinically significant differences in quality of life outcomes. J Qual Life Res. 2005;14(2):285-95

21. Cerne A, Rifel J, Rotarpavlic D, Svab J, Selic P, Kersnik J, et al. Quality of life in patients with depression, panic syndrome, other anxiety syndrome, alcoholism and chronic somatic diseases: a longitudinal study in Slovenian primary care patients. J Wien Klin Wochenschr. 2013;125(1-2):1-7.

22. Hussain A, Nygaard E, Siqveland J, Heir T. The relationship between psychiatric morbidity and quality of life: interview study of Norwegian tsunami survivors 2 and 6 years post-disaster. J BMC Psychiatry. 2016;16(1):1-9.

23. Richardson JD, Long ME, Pedlar D, Elhai JD. Posttraumatic stress disorder and health-related quality of life among a sample of treatment- and pension-seeking deployed Canadian forces peacekeeping veterans. Can J Psychiatr. 2008:53(9):594-600.

24. Misund AR, Nerdrum P, Bråten S, Pripo AH, Diseth TH, et al. Long-term risk of mental health problems in women experiencing preterm birth: a longitudinal study of 29 mothers. J Ann Gen Psychiatry. 2013;12(1):12-33.

25. Terhakopian A, Sinaii N, Engel CC, Hoge CW, Schnurr PP. Estimating population prevalence of posttraumatic stress disorder: an example using the PTSD checklist. J Trauma Stress. 2008;21(3):290-300.

26. Jia Z, Tian W, Liu W, Cao Y, Yan J, Shun ZH. Are the elderly more vulnerable to psychological impact of natural disaster? A population-based survey of adult survivors of the 2008 Sichuan earthquake. BMC Public Health. 2010;10:172.

27. Liu X, Yang Y, Yuan P, Zhang X. A study of the relationship between mental health and menstrual abnormalities in female middle school students from postearthquake Wenchuan. J Bioscience Trends. 2010;4(1):4-8. 
28. Blanchard EB, Jonesalexander J, Buckley TC, Forneris CA. Psychometric properties of the PTSD checklist (PCL). Behav Res Ther. 1996;34(8):669-73.

29. Wilkins KC, Lang AJ, Norman SB. Synthesis of the psychometric properties of the PTSD checklist (PCL) military, civilian, and specific versions. Depress Anxiety. 2011;28(7):596-606.

30. Wu Z, Xu J, Sui Y. Posttraumatic stress disorder and posttraumatic growth coexistence and the risk factors in Wenchuan earthquake survivors. J Psychiatry Res. 2016;237:49-54.

31. Zhang Z, Ran MS, Li YH, Qu GJ, Gong RR, Li RH. Prevalence of posttraumatic stress disorder among adolescents after the Wenchuan earthquake in China. J Psychol Med. 2012;42(08):1687-93.

32. Weathers FW, Keane TM, Davidson JRT. Clinician-administered PTSD scale: a review of the first ten years of research. Depress Anxiety. 2001;13(3):132-56.

33. Foa EB, Tolin DF. Comparison of the PTSD symptom scale-interview version and the clinician-administered PTSD scale. J Trauma Stress. 2000;13(2):18191.

34. Liu Y, Chen BK, Yu P, et al. Review of post-traumatic stress disorder assessment scale. Chin J Int Psychiatry. 2015;4(1):114-8.

35. Lan W, Shi QJ. Reliability and validity of Chinese version of clinician administered PTSD scale. Chin J Neural Inj Funct Reconstr. 2014;9(4):291-4.

36. Li L, Wang HM, Li Y. Development and psychometric tests of a Chinese version of the SF-36 health survey scales. Chin J Prev Med. 2002;36(2):10913.

37. Jiang MM, Li L, Wang HM. A study on the norm of Chinese population with SF-36 v2 scale, Annual meeting of Chinese Preventive Medicine Association, vol. 623; 2009.

38. Pfoh ER, Chan KS, Dinglas VD, Cuthbertson BH, Elliott D, Rorter R, et al. The SF-36 offers a strong measure of mental health symptoms in survivors of acute respiratory failure. A tri-National Analysis. Ann Am Thorac Soc. 2016; 13(8):1343-50.

39. Ware JE, Sherbourne CD. The MOS 36-item short-form health survey (SF-36): I. conceptual framework and item selection. J Med Care. 1992;30(6):473-83.

40. Bryant RA, O'Donnell ML, Creamer M. The psychiatric sequelae of traumatic injury. Am J Psychiatry. 2010;167(3):312-20.

41. Tang WJ, Zhao JD, Lu Y, Yang TT, Zhang J, Xu JP. Mental health problems among children and adolescents experiencing two major earthquakes in remote mountainous regions: a longitudinal study. Compr Psychiatry. 2016; 72:66-73.

42. Jun W. The practice and reflection of disaster social work in China. Chin J Soc Sci. 2015;9:165-81.

43. Grieger TA, Cozza SJ, Ursano RJ, Hoge C, Martinez PE, Engel CC. Posttraumatic stress disorder and depression in battle-injured soldiers. Am J Psychiatry. 2006;163(10):1777-83.

44. Galea S, Nandi A, Vlahov D. The epidemiology of post-traumatic stress disorder after disasters. Epidemiol Rev. 2005;27:78-91.

45. Breslau N. Epidemiologic studies of trauma, posttraumatic stress disorder, and other psychiatric disorders. Can J Psychiatr. 2002;47(10):923-9.

46. Schnurr PP, Hayes AF, Lunney CA, McFall M, Uddo M, et al. Longitudinal analysis of the relationship between symptoms and quality of life in veterans treated for posttraumatic stress disorder. J Consult Clin Psychol. 2006;74(4):707-13.

47. Gandek B, Sinclair SJ, Kosinski M, Ware JE. Psychometric evaluation of the SF-36[R] health survey in Medicare managed care. Health Care Financ Rev. 2004;25(4):5-25.

48. Senneseth M, Alsaker K, Natvig GK. Health-related quality of life and posttraumatic stress disorder symptoms in accident and emergency attenders suffering from psychosocial crises: a longitudinal study. J Adv Nurs. 2012; 68(2):402-13.

49. Brewin CR, Holmes EA. Psychological theories of posttraumatic stress disorder. J Clin Psychol Rev. 2003;23(3):339-76.

50. Kaushal K. Response shift Bias in pre- and post-test studies. Indian J Dermatol. 2016;61(1):91.

51. Rohs FR. Response shift bias: a problem in evaluating leadership development with self- report pretest- posttest measures. J Agric Educ. 1999:40(4):28-37.

\section{Publisher's Note}

Springer Nature remains neutral with regard to jurisdictional claims in published maps and institutional affiliations.

\section{Ready to submit your research? Choose BMC and benefit from:}

- fast, convenient online submission

- thorough peer review by experienced researchers in your field

- rapid publication on acceptance

- support for research data, including large and complex data types

- gold Open Access which fosters wider collaboration and increased citations

- maximum visibility for your research: over $100 \mathrm{M}$ website views per year

At BMC, research is always in progress.

Learn more biomedcentral.com/submissions 